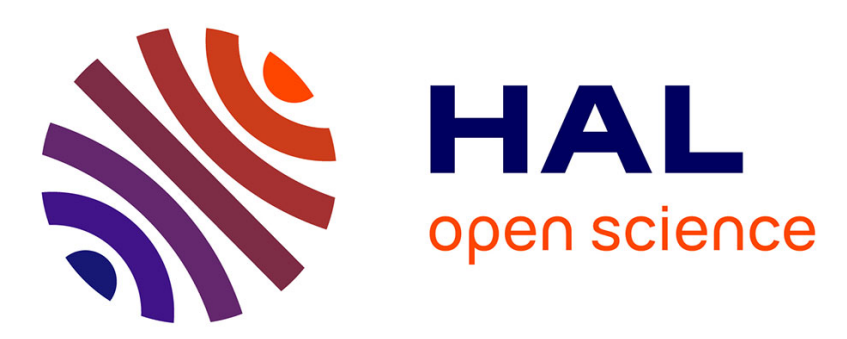

\title{
Uncertainty in open-channel discharges measured with the velocity-area method
}

J. Le Coz, B. Camenen, X. Peyrard, Guillaume Dramais

\section{To cite this version:}

J. Le Coz, B. Camenen, X. Peyrard, Guillaume Dramais. Uncertainty in open-channel discharges measured with the velocity-area method. Flow Measurement and Instrumentation, 2012, 26, p. 18 p. 29. 10.1016/j.flowmeasinst.2012.05.001 . hal-01058365

\section{HAL Id: hal-01058365 https://hal.science/hal-01058365}

Submitted on 26 Aug 2014

HAL is a multi-disciplinary open access archive for the deposit and dissemination of scientific research documents, whether they are published or not. The documents may come from teaching and research institutions in France or abroad, or from public or private research centers.
L'archive ouverte pluridisciplinaire HAL, est destinée au dépôt et à la diffusion de documents scientifiques de niveau recherche, publiés ou non, émanant des établissements d'enseignement et de recherche français ou étrangers, des laboratoires publics ou privés. 


\title{
Uncertainty in open-channel discharges measured with the velocity-area method
}

\author{
J. Le Coz ${ }^{*, a}$, B. Camenen ${ }^{\mathrm{a}}$, X. Peyrard ${ }^{\mathrm{a}}$, G. Dramais ${ }^{\mathrm{a}}$ \\ ${ }^{a}$ Irstea (Cemagref), UR HHLY, Hydrology-Hydraulics \\ 3 bis quai Chavveau, CP 220 F-69336, Lyon Cedex 09, France
}

\begin{abstract}
A large part of the discharge measurements conducted in open-channels are performed using the velocityarea method, which consists of sampling flow velocity and depth throughout the cross-section for discrete integration of discharge. To address the limitations of the method proposed by the ISO 748 standard, a generalized approach is introduced for computing the uncertainty associated with velocity-area discharge measurements. Direct computation methods are suggested for estimating the uncertainty components related to the vertical integration of velocity and to the transversal integration of velocity and depth. Discharge extrapolations to the edges and in the top/bottom layers are explicitly taken into account, as well as the distribution of the verticals throughout the cross-section. The new uncertainty analysis method was applied to varied stream discharge measurements, and the results are discussed and compared with the results obtained following the ISO 748 standard method. Similar results were obtained for standard measurements conducted in natural sections, while more variable and more relevant uncertainty levels were computed for less standard cases, especially in man-made canals with regular shapes and low width-to-depth ratios. The new method appears to be more versatile than the ISO 748 method, while as simple and robust. It can be easily implemented in usual discharge computation software. Some perspectives are drawn for improving the assessment of instrumental and environmental error sources, including errors due to variable discharge. Further validation tests still need to be conducted, but the method already provides interesting results, especially in terms of the contribution of the different error sources. It constitutes a useful practical tool to conduct sensitivity analysis and to plan and improve the measurement strategy.
\end{abstract}

Key words: hydrometry, discharge measurement, uncertainty analysis, velocity-area method, stream-gauging

\section{Introduction}

\subsection{Stream discharge measurements following the velocity-area method}

The water discharge of natural and artificial streams is a key parameter for hydrologic studies and policy decisions regarding water resources, biological habitat and natural hazards. Like any other type of measurement, stream discharge measurements are not complete if the associated uncertainty, typically a confidence interval half-width at $95 \%$ level, is not provided along with the central value. Without an estimation of the discharge uncertainty, the data user is not able to assess the errors potentially induced in his/her conclusions, such as the costs related with flood damages, the report of an infringement to water use regulations, or the evaluation of the accuracy of a hydrological model.

Instantaneous or quasi-instantaneous stream discharges may be measured using a variety of techniques (e.g. 18, 9, 5), most of which require a costly amount of field work. The most popular technique is the velocity-area method, which consists of a discrete integration of flow velocity over the channel crosssection. Velocities and water depths are sampled at given positions on verticals distributed throughout

\footnotetext{
${ }^{*}$ Corresponding author. Tel: +33 472208786; fax: +33478477875

Email address: jerome.lecoz@irstea.fr (J. Le Coz) 
the section (Fig. 1). At a given vertical $j(1 \leq j \leq m)$, the following parameters are measured: distance from the start edge $y_{j}$, water depth $d_{j}$, and point velocities perpendicular to the cross-section $v_{j, k}$ measured at depths $d_{j, k}$. While distances are measured using conventional calibrated devices, point velocities are measured with either mechanical (propellers), electro-magnetic (Hall effect based), or acoustic (Doppler effect based) current-meters, which are typically mounted on a wading-rod, or deployed from a cableway or from a bridge.

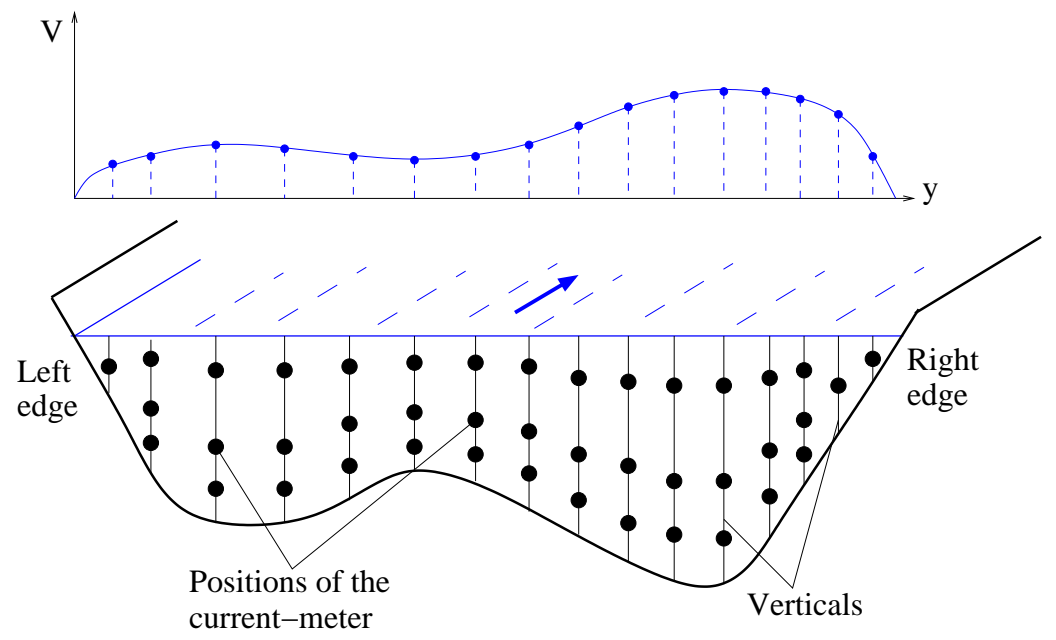

Figure 1: Principle of the velocity-area method: discrete sampling of velocity and depth throughout a cross-section, and the corresponding profile of depth-averaged velocity.

(a)

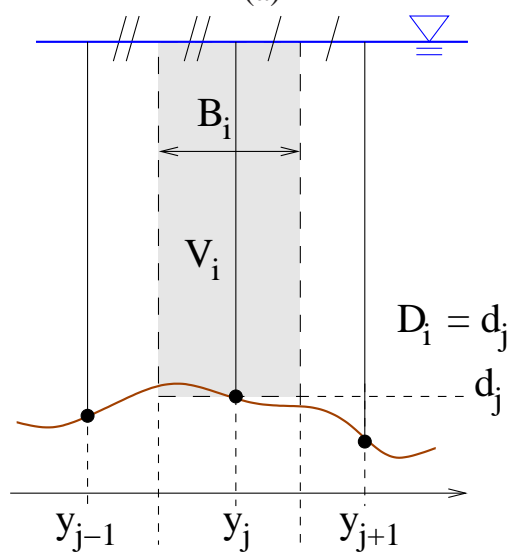

(b)

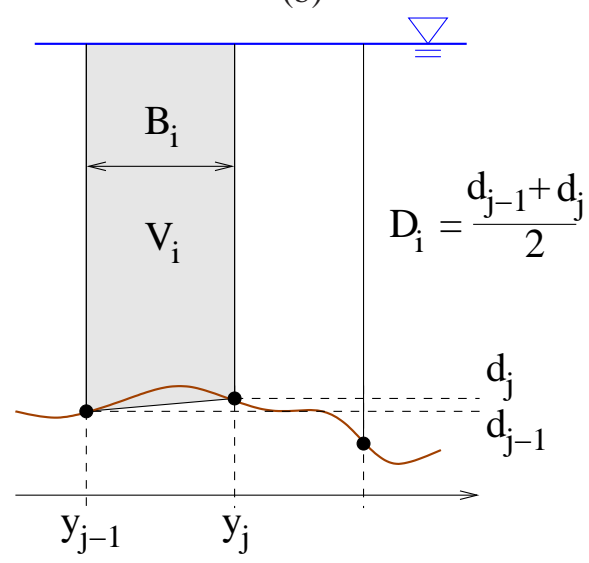

Figure 2: Principle of the conventional discharge integration techniques: the mid-section (a) and the mean-section (b) methods.

The total discharge, $Q$, is the sum of partial discharges $Q_{i}$ over the $N$ subsections $i$ of the cross-section:

$$
Q=\sum_{i=1}^{N} Q_{i}=\sum_{i=1}^{N} B_{i} D_{i} V_{i}
$$

with $B_{i}, D_{i}$, and $V_{i}$, the width, mean depth, and mean normal velocity of each subsection $i$, respectively.

The most commonly used integration techniques are the mid-section and the mean-section methods (see Fig. 2), which produce equal area results and similar discharge results (within $1 \%$ typically). Following the mid-section method, a subsection is a rectangle centred in a vertical and extending to half-distance from neighbouring verticals (Fig. 2a). The subsection depth and mean velocity are the depth and depth-averaged velocity measured at the vertical of interest. Following the mean-section method, a subsection is a trapeze 
based on two successive verticals, and the subsection mean velocity is the average of the depth-averaged velocities measured at each vertical (Fig. 2b).

In both methods, at each vertical $j$ the depth-averaged velocity $\overline{v_{j}}$ is computed either as a weighted sum of point velocities measured at standard positions above the bed (reduced point methods, 4) or directly by linear interpolation (velocity distribution method, 4). In addition there is the more seldomly used integration method [4], in which the velocity is physically integrated by continuously lowering and raising the current-meter over most of the flow depth. In the velocity distribution method and the integration method, velocities need to be extrapolated down to the bed (bottom layer) and up to the free-surface (top layer), assuming either a power, a linear or a constant function. Like velocities in the top and bottom layers, the mean velocity in the subsection delineated by the first/last vertical and the bank $(i=1$ or $i=N)$ also has to be extrapolated, usually using a coefficient derived from a power function, according to the law of the wall.

\subsection{Uncertainty analysis of velocity-area discharge measurements}

The identification and the estimation of errors in velocity-area discharge measurements were addressed by several authors (e.g., 6, 18, 17, 19). Based on a broad literature review (more than 140 publications), Pelletier [17] classified uncertainties according to the following error sources: sampling the cross-sectional area, sampling the mean velocity in time, sampling the mean velocity in space (both vertically and transversally), current-meter errors (including a variety of effects), and differences in the discharge computation procedure. Uncertainties related to top, bottom, or edge velocity extrapolations were not considered independently.

However, such reviews and estimations of errors do not provide a framework for performing uncertainty analysis according to metrological standards. The ISO/TS 25377 [2], or Hydrometric Uncertainty Gidance (HUG), provides a general hydrometric uncertainty framework following the GUM [1] approach. However, the most common framework followed for assessing uncertainty in velocity-area discharge measurements remains the method presented in the ISO 748 [4] standard. Typically, the HUG does not provide practical guidelines for assessing the uncertainty in velocity-area methods, and it refers to the ISO 748 standard as regards the values for integration uncertainty components. Herschy [10] showed that the ISO 748 method conceptually complies with the GUM [1] uncertainty analysis framework, referred to as the Guide to the expression of uncertainty in measurement (GUM). Following a first-order approximation, the equation for the combined uncertainty in measured discharge $u(Q)$ proposed by the ISO 748 standard is $^{1}$ :

$$
u^{2}(Q)=u_{s}^{2}+u_{m}^{2}+\frac{\sum Q_{i}^{2}\left[u^{2}\left(B_{i}\right)+u^{2}\left(D_{i}\right)+u_{p}^{2}\left(V_{i}\right)+\frac{1}{n_{i}}\left[u_{c}^{2}\left(V_{i}\right)+u_{e}^{2}\left(V_{i}\right)\right]\right]}{\left(\sum Q_{i}\right)^{2}}
$$

with the following uncertainty components:

- $u_{s}$ accounting for systematic errors remaining after the best calibration of velocity, width and depth measuring devices

- $u_{m}$ accounting for errors due the limited number $m$ of verticals (transversal integration of depth and velocity)

- $u\left(B_{i}\right)$ and $u\left(D_{i}\right)$, accounting for random errors in width and depth measurements, respectively

- $u_{p}\left(V_{i}\right)$ accounting for errors due to the limited number $n_{i}$ of point velocity measurements over vertical $i$ (vertical integration of velocity)

- $u_{c}\left(V_{i}\right)$ and $u_{e}\left(V_{i}\right)$, accounting for random errors in point velocity measurements due to the limited current-meter accuracy and due to time-averaging of turbulent fluctuations over the time of exposure, respectively

\footnotetext{
${ }^{1}$ Note that all uncertainty components written $u(X)$ in this document are relative standard uncertainties (in $\%$ of measurand $X$ ). As is usually done and is recommended by the the ISO/TS 25377 [2], the final uncertainty $U=k u$ is expressed using a coverage factor $k=2(95 \%$ level of confidence)
} 
For a sufficient number of verticals $(m \geq 10)$ and a constant number $n$ of velocity measurements per vertical, if partial discharges $Q_{i}$ are roughly equal, and assuming that uncertainty components are also roughly equal over the verticals, then the equation may be simplified as follows [4]:

$$
u^{2}(Q)=u_{s}^{2}+u_{m}^{2}+\frac{1}{m}\left[u^{2}(B)+u^{2}(D)+u_{p}^{2}+\frac{1}{n}\left[u_{c}^{2}+u_{e}^{2}\right]\right]
$$

Assuming a proper calibration of instruments, typical values are suggested by Herschy [10] and ISO 748 [4]: $u_{s}=1 \%, u(B)=u(D)=0.5 \%$. In its Appendix E, the ISO 748 standard also provides informative values for $u_{m}$ according to the number of verticals $m, u_{p}$ according to the vertical velocity integration method and to the number of velocity points, $u_{c}$ according to the measured velocity and type of current-meter rating (Individual versus Group or standard rating), $u_{e}$ according to the measured velocity, exposure time, and position in the vertical. For ease of use, in this study, the ISO 748 standard informative values for uncertainty components $u_{m}, u_{p}, u_{c}$, and $u_{e}$ were interpolated using power function fits, such as $u_{m}=32 m^{-0.88}$.

\subsection{The necessity of a generalized method for computing uncertainty}

Though the uncertainty analysis framework proposed by the ISO 748 [4] standard is a solid reference method, its application to the diversity of velocity-area discharge measurements made by hydrometry services is problematic. The uncertainty analysis method is well suited to 'standard' discharge measurements which comply with all the requirements of ISO 748 standard. In such cases, the computed uncertainty usually lies between $5 \%$ and $7 \%$. However, for a number of non-standard measurements, the uncertainty values obtained with this method appear to be irrelevant.

More precisely, the following drawbacks of the ISO 748 uncertainty analysis method may be identified:

1. Because informative values given in Appendix E for uncertainty components are derived from empirical studies, they are specific to an instrument type and to some measurement conditions.

2. Top, bottom, and edge velocity extrapolations are not taken into account in the uncertainty analysis, though their contribution may not be negligible.

3. When vertical integration of velocity is performed directly (velocity distribution method), a negligible default value $(0.5 \%)$ is attributed to $u_{p}$. For non-standard measurements with not enough velocity points and often significant top/bottom extrapolations, the value of $u_{p}$ should be taken higher than $0.5 \%$.

4. Most of the computed uncertainty usually stems from the term $u_{m}$, which is an empirical function of the number of verticals $m$, with no consideration of the spatial distribution of verticals, compared to the transversal variation in bed geometry and flow distribution.

5. Time-integration error in the case of varying discharge during the measurement is not estimated, as well as the discharge deviation to the steady conditions due to transient flow effects (hysteresis).

For all these reasons, it appears necessary to propose a more versatile approach for computing the uncertainty associated with velocity-area discharge measurements. This paper presents proposals for addressing the above mentioned limitations of the ISO 748 standard methodology. Simple new protocols for computing the uncertainty related to vertical velocity integration and to transversal velocity and depth integration are detailed. The new uncertainty analysis method is then applied to varied examples of openchannel discharge measurements, and the results are discussed and compared with the ISO 748 standard results. Finally, a discussion on error sources, including errors due to variable discharge, provides guidelines for improving the measurement strategy and draws perspectives for the extension of the method to other discharge measurement techniques.

\section{Quantifying uncertainty due to spatial integration}

\subsection{Vertical integration of velocity}

Since the uncertainty values provided by the ISO 748 standard for reduced point methods for 1, 2, 3, 5 and 6 points are based on comprehensive experimental studies, no change in the estimation of these values is proposed. 
Due to the limitations of the ISO 748 standard mentioned above, a new approach is proposed for estimating the uncertainty related to the velocity distribution method which is based on linear interpolation in the measured layer, along with extrapolation options in the top/bottom layers. The uncertainty $u_{p}\left(\overline{v_{j}}\right)$ in the depth-averaged velocity $\overline{v_{j}}$ at a vertical $j$ due to the vertical integration procedure is more easily computed as equal to the vertical integration uncertainty $u_{p}\left(q_{j}\right)$ in the discharge per unit width $q_{j}\left(\mathrm{~m}^{2} / \mathrm{s}\right)$. The errors due to the computation procedure of the interpolated (or 'measured') discharge and of the extrapolated (or 'top/bottom') discharge are considered to be independent, even if some velocity measurements are used for both operations. Indeed, interpolation and extrapolation of discharges are different in essence, for extrapolation requires the assumption of a vertical velocity distribution based on theoretical or empirical considerations. Thus, the uncertainty due to the vertical integration procedure is:

$$
u_{p}^{2}\left(\overline{v_{j}}\right)=u_{p}^{2}\left(q_{j}\right)=u_{p}^{2}\left(q_{j, \text { meas }}\right)+u_{p}^{2}\left(q_{j, \text { top } / \text { bot }}\right)
$$

To assess the uncertainty due to interpolation, $u_{p}\left(q_{j, \text { meas }}\right)$, the maximum discharge error between adjacent points $k$ and $k+1$ is estimated to be $\Delta q_{j, k}=\left|\left(v_{j, k}-v_{j, k+1}\right)\left(d_{j, k}-d_{j, k+1}\right)\right| / 2$ (see Fig. 3). This estimation is based on the assumption of a real velocity distribution which would be convex and lie somewhere between the linear interpolation and the maximum of both velocity values $v_{j, k}$ and $v_{j, k+1}$. Therefore, assuming a rectangular probability density function for interpolation errors, the uncertainty in the measured discharge is computed as follows [1]:

$$
u_{p}^{2}\left(q_{j, \text { meas }}\right)=\frac{1}{12 q_{j}^{2}} \sum\left[\left(v_{j, k}-v_{j, k+1}\right)\left(d_{j, k}-d_{j, k+1}\right)\right]^{2}
$$

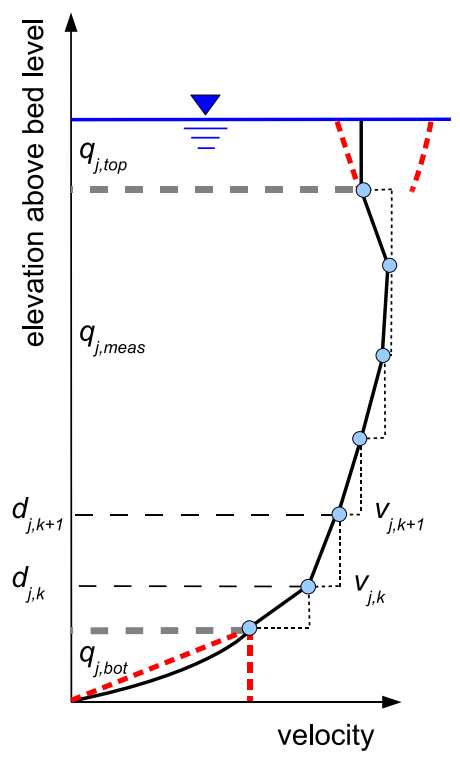

Figure 3: Principle of the computation of the maximum depth-average velocity error due to discrete sampling of velocities in the measured layer and to velocity extrapolation options in top and bottom layers. In the top layer, the illustrated options are the constant extrapolation (black solid line), and the power fit and the linear fit on the highest two points (red dashed lines). In the bottom layer, the illustrated options are the power fit (black solid line), and the constant and the linear-to-zero extrapolations (red dashed lines).

Similarly, the uncertainty due to extrapolation $u_{p}\left(q_{j, t o p / b o t}\right)$ is assessed based on maximum discharge errors in top and bottom layers, assuming a rectangular probability density function for extrapolation errors [1]:

$$
u_{p}\left(q_{j, t o p / b o t}\right)=\frac{\Delta q_{j, t o p}+\Delta q_{j, b o t}}{2 \sqrt{3} q_{j}}
$$

The maximum error in top discharge, $\Delta q_{j, t o p}$, is estimated considering the maximum deviation of the usual extrapolation options to the constant extrapolation (see Fig. 3). The extreme options yielding the 
potentially greatest deviations are considered: the linear fit on the highest two points and the power fit with exponent $1 / 2$ (roughest bottom case) and 1/10 (smoothest bottom case). The maximum error in top discharge is taken as twice the maximum deviation of the discharge computed using any extrapolation options, $q_{j, t o p}^{\text {options }}$, to the constant extrapolation discharge, $q_{j, t o p}^{c s t}$ :

$$
\Delta q_{j, t o p}=2 \max _{\text {options }}\left|q_{j, \text { top }}^{\text {options }}-q_{j, \text { top }}^{\text {cst }}\right|
$$

The reason for taking a coefficient 2 is because in the worst-case scenario the velocity profile may decrease as well as increase up to the free-surface.

Since the worst-case scenarii are assumed to be a linear velocity profile to zero at the bed level, and a constant velocity profile (see Fig. 3), the maximum error in bottom discharge is simply computed as:

$$
\Delta q_{j, b o t}=\frac{1}{2} q_{j, b o t}^{c s t}
$$

As discussed in Section 3.4, this formulation of $u_{p}\left(q_{j}\right)$, or equivalently $u_{p}\left(\overline{v_{j}}\right)$, yields uncertainty values that are consistent with the values provided by the ISO 748 standard for the velocity distribution method in the case of standard discharge measurements.

The case of the integration method is not treated explicitly by the ISO 748 standard. In the absence of comprehensive uncertainty studies on this method, we propose to consider that the uncertainty due to vertical integration is negligible in the measured part of the profile, thanks to physical averaging. In this case, $u_{p}\left(\overline{v_{j}}\right)$ only arises from uncertainty in extrapolated discharges, usually in the bottom layer only. However, the number of independent velocity measurements, $n_{j}$, is equal to the number of complete current-meter cycles at vertical $j$. Since $n_{j}$ is usually equal to 1 or 2 , and since the exposure time range is usually 30100 seconds, the contribution of current-meter uncertainty $\left(u_{c}, u_{e}\right)$ to the final uncertainty is as high as in the case of 1 or 2-point measurements.

Finally, the uncertainty $u_{p}\left(V_{i}\right)$ in the subsection-averaged velocity depends on the selected discharge computation method. In the case of the mid-section method, since the depth-averaged velocity $\overline{v_{j}}$ at vertical $j$ is applied to the surrounding subsection, i.e. $V_{i}=\overline{v_{j}}$, the corresponding uncertainties are equal:

$$
u_{p}\left(V_{i}\right)=u_{p}\left(\overline{v_{j}}\right)
$$

In the case of the mean-section method, since the mean of $\overline{v_{j}}$ and $\overline{v_{j+1}}$ is applied to the subsection, i.e. $V_{i}=\left(\overline{v_{j}}+\overline{v_{j+1}}\right) / 2$, the resulting uncertainty is:

$$
u_{p}\left(V_{i}\right)=\frac{1}{2} \sqrt{u_{p}^{2}\left(\overline{v_{j}}\right)+u_{p}^{2}\left(\overline{v_{j+1}}\right)}
$$

\subsection{Transversal integration of depth}

A new method is proposed for estimating the uncertainty due to errors in the transversal integration of depths and depth-averaged velocities. Instead of the single term $u_{m}$ of the ISO 748 standard, the transversal integration uncertainties in each subsection-averaged depth, $u_{m}\left(D_{i}\right)$, and in each subsection-averaged velocity, $u_{m}\left(V_{i}\right)$, are computed. This leads to the following equation, modified from Eq.2:

$$
u^{2}(Q)=u_{s}^{2}+\frac{\sum Q_{i}^{2}\left[u^{2}\left(B_{i}\right)+u^{2}\left(D_{i}\right)+u_{p}^{2}\left(V_{i}\right)+u_{m}^{2}\left(D_{i}\right)+u_{m}^{2}\left(V_{i}\right)+\frac{1}{n_{i}}\left[u_{c}^{2}\left(V_{i}\right)+u_{e}^{2}\left(V_{i}\right)\right]\right]}{\left(\sum Q_{i}\right)^{2}}
$$

To assess $u_{m}\left(D_{i}\right)$, the maximum error in depth $\Delta D_{i}$ due to transversal integration, or equivalently the maximum error in subsection area $S_{i}=B_{i} D_{i}$, is estimated using the stream discharge measurement dataset. Assuming a rectangular probability density function for integration errors [1], the transversal integration uncertainty in $D_{i}$ is:

$$
u_{m}\left(D_{i}\right)=\frac{\Delta D_{i}}{2 \sqrt{3}}
$$

Similar approaches were recently investigated by other authors, such as Kiang et al. [12] and Olivier et al. [16], the fundamental difference laying in the way $\Delta D_{i}$ is estimated. Kiang et al. [12] and Olivier 
et al. [16] introduced methods applied to the mid-section procedure, for which $D_{i}=d_{j}$. The first method estimates $\Delta D_{i}$ from the deviation of $D_{i}$ from the linear interpolation of $D_{i-1}$ and $D_{i+1}$. The second method simply states $\Delta D_{i}=\left|D_{i-1}-D_{i+1}\right|$. A possible generalization of the latter method is to state $\Delta D_{i}=\mid D_{i-1}-$ $D_{i}|+| D_{i}-D_{i+1} \mid$. Kiang et al. [12] suggest computing the velocity uncertainty $u_{m}\left(V_{i}\right)$ the same way as $u_{m}\left(D_{i}\right)$, whereas Olivier et al. [16] assume that $u_{m}\left(D_{i}\right)$ is representative of both error sources.

Several problems may arise with these methods. In some cases where measured depths show almost linear or constant evolution, both methods may severely underestimate the uncertainty in depth, because $\Delta D_{i}$ estimate is small whereas the bed elevation may vary significantly between verticals. Moreover, for the same reason larger spacing between verticals may not directly increase the computed uncertainty, and even decrease it in some cases. Last, previously known information on the bathymetry or velocity profiles in the measuring site cannot be directly taken into account.

To tackle these drawbacks, while keeping the computation method simple, we propose to estimate $\Delta D_{i}$ based on the $\min / \max$ realistic subsection areas, $S_{i, \min }$ and $S_{i, \max }$, derived from physically or empirically justified assumptions on the bathymetry cross-profile:

$$
\Delta D_{i}=\frac{S_{i, \max }-S_{i, \min }}{B_{i}}
$$

The most simple way to compute $S_{i, \min }$ and $S_{i, \max }$ is to fix a user-defined angle $\alpha$ to account for the maximum bottom transverse slope, including irregularity of the ground such as pools or boulders for instance. The angle $\alpha$ may be determined from physical assumptions related to the nature of the stream bed, or using available bathymetry measurements, or the known geometry of a man-made canal, etc. The choice of a value for $\alpha$ will be discussed along with the presentation of test cases. A maximum value is often induced by bed-material stability considerations (typically $\sim 40^{\circ}$ for a granular bed). A minimum value should be the maximum slope between two adjacent verticals in the measurement dataset. Exploring this interval, sensitivity tests are useful to assess the variation in the computed uncertainty.

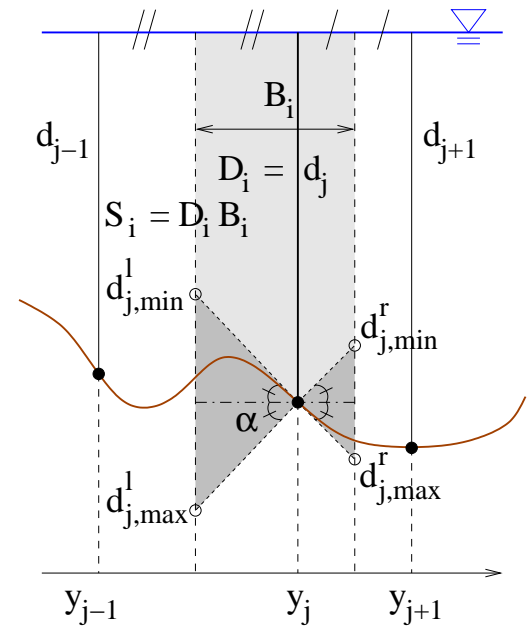

(a)

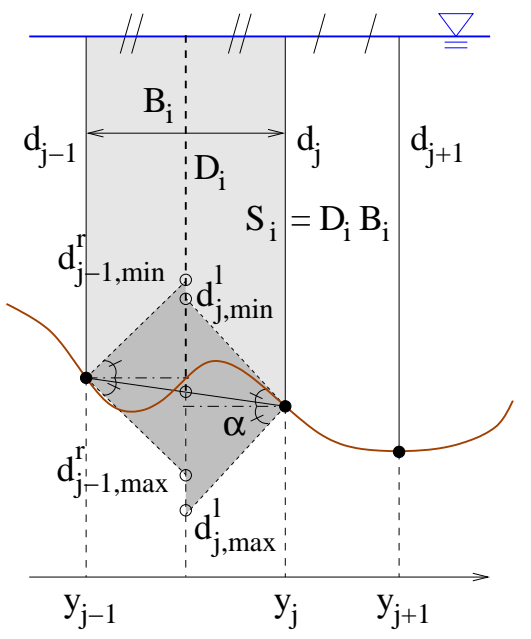

(b)

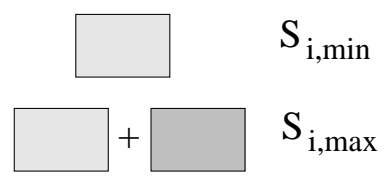

Figure 4: Principle of the computation of the maximum error on subsection depth due to sampling of the bed geometry: (a) midsection integration method, (b) mean-section integration method.

The principle of the method is illustrated in Fig. 4 for both mid-section and mean-section procedures. The method is symmetrical for both procedures. It applies normally to the edge subsection, since the depths at the edges are given like at other verticals. It should be noted that $\alpha$ is used to estimate the maximum variation in wetted areas, and not to accurately simulate realistic scenarii for the bed profile. Therefore, the apparent discontinuity in bed profiles is not a problem. However, since the bottom cannot exceed the freesurface the highest bed line is limited to the water level at each subsection. When this local correction is not to be applied, the following simple formulas are obtained for mid-section and mean-section procedures, respectively: 


$$
\begin{array}{lr}
u_{m}\left(D_{i}\right)=\frac{b_{i}}{4 \sqrt{3}} \tan \alpha & \text { (mid - section) } \\
u_{m}\left(D_{i}\right)=\frac{b_{i+1}^{2}+b_{i}^{2}}{8 \sqrt{3}\left(b_{i+1}+b_{i}\right)} \tan \alpha & \text { (mean - section) }
\end{array}
$$

with $b_{i}=y_{j}-y_{j-1}$ and $b_{i+1}=y_{j+1}-y_{j}$.

\subsection{Transversal integration of velocity and edge extrapolation}

We propose a similar method for computing $u_{m}\left(V_{i}\right)$ from the maximum error in velocity $\Delta V_{i}$ due to transversal integration. Assuming a rectangular probability density function for integration errors [1], the transversal integration uncertainty in $V_{i}$ is:

$$
u_{m}\left(V_{i}\right)=\frac{\Delta V_{i}}{2 \sqrt{3}}
$$

To be consistent with the determination of $u_{m}\left(D_{i}\right)$, worst-case velocity distributions throughout the subsection are interpolated based on the worst-case bed profiles computed previously. We use a $\sqrt{d}$ interpolation of depth-averaged velocities $\bar{v}$, which may be related to the assumption of a constant or linearly varying Froude number [7] or Chézy coefficient [5], with the hydraulic radius $R_{h}$ being approximated by the local depth $d$.

In practice, the $\overline{v_{j}} / \sqrt{d_{j}}$ ratio is computed at each vertical $j$, with a zero value assumed at the edges of the cross-section. Then $\bar{v} / \sqrt{d}$ is linearly interpolated at half-distances between verticals, where $\min / \mathrm{max}$ local depths were previously estimated (see Fig. 4). Resulting min/max local velocities can be integrated linearly over the subsection to compute the min/max subsection velocities, $V_{i, \min }$ and $V_{i, \max }$, hence:

$$
\Delta V_{i}=V_{i, \max }-V_{i, \min }
$$

As for computing $u_{m}\left(D_{i}\right)$, the method is symmetrical for both mid-section and mean-section procedures, and the apparent discontinuity in the velocity profile is not a problem since the purpose is not to simulate realistic velocity distributions, but to estimate $\min / \max$ variations in the subsection-averaged velocity.

The case of the edge subsections, which are comprised between each bank and the adjacent vertical, is specific because the subsection velocity is determined by extrapolation, not by interpolation of measured velocities. As is usually done, at the edge subsection $(i=1$ or $i=N)$, we compute the velocity based on a power velocity extrapolation to the wall, with exponent $1 / m_{1 / N}$ :

$$
\begin{aligned}
V_{1} & =\frac{m_{1}}{m_{1}+1} \overline{v_{1}} \\
V_{N} & =\frac{m_{N}}{m_{N}+1} \overline{v_{m}}
\end{aligned}
$$

The ISO 748 standard indicates that generally, $m_{1 / N}$ lies between 5 and 7 but it may vary over a wider range depending on the hydraulic resistance. Typical stream discharge measurements suggest $m_{1 / N}$ values varying from 2 (very rough, sloped bank) to 10 (very smooth, vertical bank). Therefore, at the edge subsections the maximum mean velocity error $\Delta V_{1 / N}$ is computed using these two extreme values:

$$
\Delta V_{1 / N}=\left(\frac{10}{11}-\frac{2}{3}\right) \overline{v_{1 / m}} \approx 0.24 \overline{v_{1 / m}}
$$

\section{Application of the proposed methods to test cases}

\subsection{Presentation of the test cases}

A representative set of stream discharge measurements in varied conditions (Tab.1) was selected to show and discuss the results of the proposed new method, in comparison with the results of the classical ISO 748 method (Eq. 3). The mid-section procedure was always followed to compute discharges. The 
(a) Arc
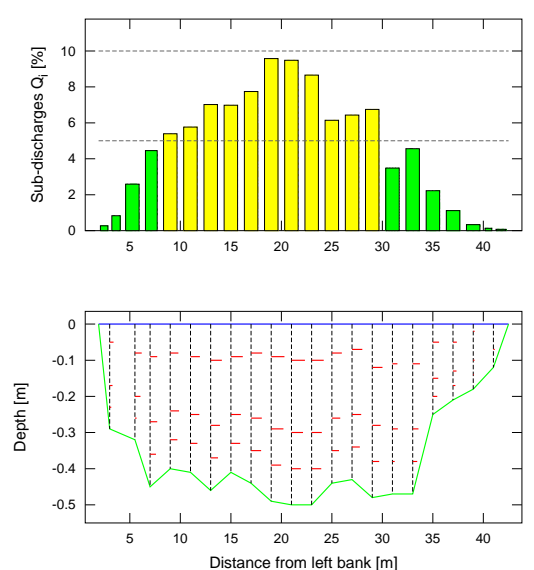

(c) Gignac
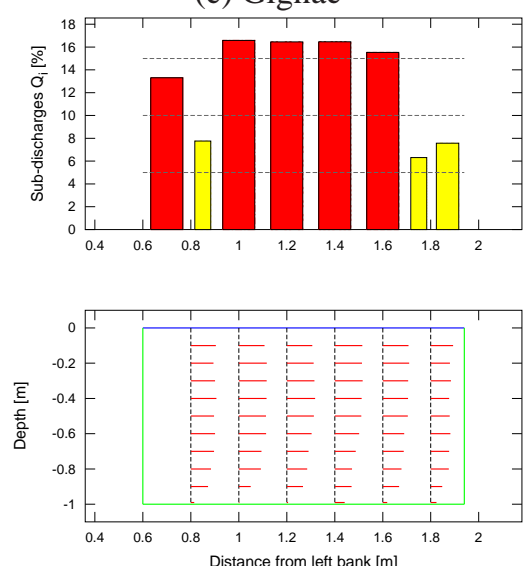

(e) Doller
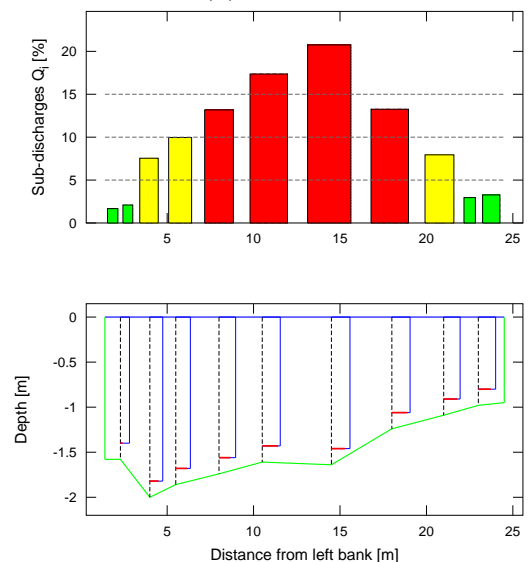

(b) Ardèche
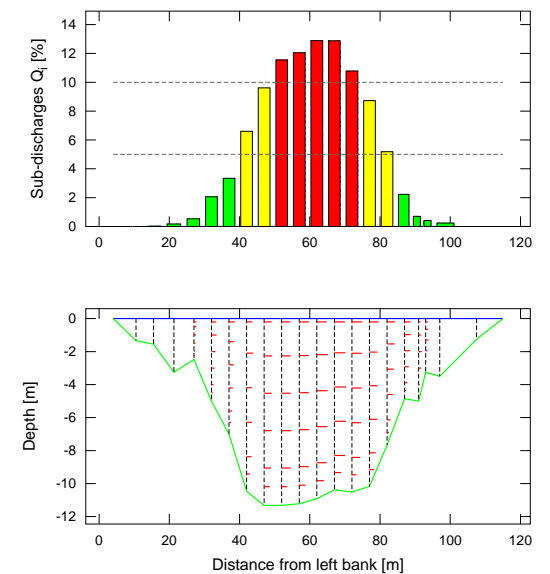

(d) Laboratory
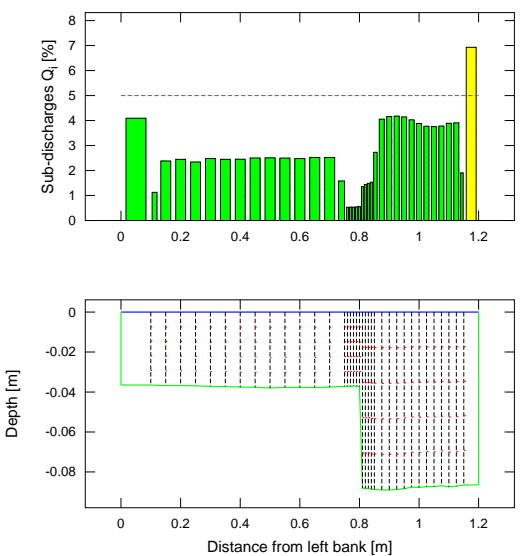

Figure 5: Test cases: measured depths and point velocities (bottom) and computed sub-discharges (top). 


\begin{tabular}{c|c|c|c|c|c|c|c} 
name & section type & $\begin{array}{c}\text { velocity } \\
{[\mathrm{m} / \mathrm{s}]}\end{array}$ & $\begin{array}{c}\text { width } B \\
{[\mathrm{~m}]}\end{array}$ & $\begin{array}{c}\text { depth } D \\
{[\mathrm{~m}]}\end{array}$ & $B / D$ & $m$ & $n$ \\
\hline Arc & mountain river & 1 & 40 & 0.4 & 100 & 20 & 3 \\
Ardèche & lowland river & 3 & 80 & 10 & 8 & 17 & 6 \\
Gignac & irrigation canal & 0.5 & 1.34 & 1.00 & 1.34 & 6 & 10 \\
Laboratory & compound channel & 0.5 & 1.20 & 0.05 & 22 & 36 & 4 \\
Doller & lowland river & 1.8 & 23 & 1.5 & 15 & 9 & $1^{*}$
\end{tabular}

Table 1: Main characteristics of the stream discharge measurements used as test cases $\left({ }^{*}\right.$ number of current-meter cycles in the integration method).

following discussions and conclusions also apply for the mean-section procedure, because differences in computed discharge components and uncertainty components are almost always negligible.

The first example, the Arc-en-Maurienne river at Saint-Avre, France (Fig. 5a), is typical of low flow conditions in a small mountain river with a large width-to-depth ratio: $B / D \approx 100$. Measurements were conducted using an electromagnetic current-meter (Ott Nautilus) mounted on a wading rod, also used to read flow depths. The ISO 748 procedure for 3 velocity points over 20 verticals was followed, except at the last vertical where only one velocity was measured due to shallowness. Extrapolated edge discharges are negligible compared to total discharge. As can be seen in the subsection discharge histogram (see Fig. 5a, top), this stream discharge measurement meets the ISO 748 requirements since all subdischarges are lower than $10 \%$ of total discharge. In that sense, this measurement will be qualified as 'standard'.

The second example, the Ardèche river at Sauze, France (Fig. 5b), was chosen as representative of flood conditions in a larger river with a much smaller width-to-depth ratio: $B / D \approx 8$. Measurements were conducted using a horizontal-axis propeller current-meter (Ott C31) mounted on a 80-kg torpedo deployed from a cableway. The ISO 748 procedure for 6 velocity points was followed.Seventeen verticals were distributed throughout the cross-section so as to sample more densely the areas where the discharge was higher, near the centre of the flow. Even so, the 5 central subsections show partial discharges that slightly exceed the $10 \%$ threshold recommended by the ISO 748 standard. Nevertheless, this measurement can be regarded as 'standard'. Here again, extrapolated edge discharges are negligible.

The third example, a small man-made irrigation canal at Gignac, France (Fig. 5c), provides typical dense velocity sampling over a limited number of verticals throughout a narrow rectangular cross-section, with a width-to-depth ratio close to one: $B / D=1.34$. Vertical velocity profiles were comprehensively sampled at 10 positions every $10 \mathrm{~cm}$ plus a near-bed position as deep as possible ( $1 \mathrm{~cm}$ above bottom) using a micro-propeller. Due to the narrow section and to the duration of velocity measurements, only 6 verticals were used. As a consequence, most subdischarges are greater than $15 \%$ of total discharge, and extrapolated edge discharges yield large contributions (13\% and $8 \%)$ to total discharge. At both banks, the velocity variation suggests roughness coefficients $m_{1 / N} \approx 6$, which is consistent with smooth concrete walls. This example measurement is far from 'standard', according to the ISO 748 standard.

The fourth example does not relate to a field site, but a laboratory compound-channel flume (Fig. 5d) where 4 velocity points (every $0.2 h$ ) were measured over a high number of verticals (36) with a micropropeller. Since no 4-point formula is available in ISO 748 standard, velocity can be vertically averaged using either the velocity distribution method or the 3-point formula (reduced point method). This example is interesting to study because it is representative of an ideally dense velocity sampling (each subdischarge is lower than $5 \%$ of total discharge), in a quasi-perfect compound rectangle geometry (visible irregularities in depth profile are due to free-surface deformation), for controlled steady-flow conditions. The compound geometry and the induced velocity distribution are typical of an overbank flood flow in a wide $\operatorname{river}(B / D \approx$ $22)$, with complex hydraulic processes at the interface. Near the very smooth walls made of PVC, inferred roughness coefficients are high $\left(m_{1 / N} \approx 10\right)$. Due to technical restrictions, edge verticals are not as close to the walls as needed ideally, and extrapolated edge discharges are significant (4\% and $7 \%$ of total discharge).

The fifth example, the Doller river at Burnhaupt, France (Fig. 5e), is a typical discharge measurement conducted in a medium size stream $(B / D \approx 15)$ following the integration method. Measurements were conducted using a horizontal-axis propeller current-meter deployed from a bridge. The distribution of the nine verticals intended to better sample the flow and depth variations in the deepest left part of the cross- 
section, rather than minimizing the subdischarges, which exceed the $10 \%$ and even the $15 \%$ thresholds in the central part. Roughness coefficients were fixed to $m_{1 / N}=3$ at the edges, and $m_{b}=6$ for extrapolation of the bottom discharge.

\subsection{Overall comparison of the results}

To assess the results of the proposed uncertainty method, Eq. 11 is rearranged as follows:

$$
u^{2}(Q)=u_{s}^{2}+u_{B, D}^{2}+u_{p}^{2}+u_{m}^{2}(V, D)+u_{e d}^{2}+u_{c, e}^{2}
$$

Relevant components have been gathered to form the mean uncertainty terms related to random errors in width and depth measurements $\left(u_{B, D}\right)$, in velocity vertical integration $\left(u_{p}\right)$, in transversal integration of velocity and depth $\left(u_{m}(V, D)\right.$ and $u_{e d}$ for edge subsections), and in point velocity measurements $\left(u_{c, e}\right)$ :

$$
\begin{aligned}
u_{B, D}^{2} & =\sum Q_{i}^{2}\left[u^{2}\left(B_{i}\right)+u^{2}\left(D_{i}\right)\right] / Q^{2} \\
u_{p}^{2} & =\sum Q_{i}^{2} u_{p}^{2}\left(V_{i}\right) / Q^{2} \\
u_{m}^{2}(V, D) & =\sum_{1<i<N} Q_{i}^{2}\left[u_{m}^{2}\left(V_{i}\right)+u_{m}^{2}\left(D_{i}\right)\right] / Q^{2} \\
u_{e d}^{2} & =Q_{1}^{2}\left[u_{m}^{2}\left(V_{1}\right)+u_{m}^{2}\left(D_{1}\right)\right] / Q^{2}+Q_{N}^{2}\left[u_{m}^{2}\left(V_{N}\right)+u_{m}^{2}\left(D_{N}\right)\right] / Q^{2} \\
u_{c, e}^{2} & =\sum Q_{i}^{2}\left[\frac{1}{n_{i}}\left[u_{c}^{2}\left(V_{i}\right)+u_{e}^{2}\left(V_{i}\right)\right]\right] / Q^{2}
\end{aligned}
$$

Tab. 2 presents the uncertainty results of both the ISO 748 method (Eq. 3) and the new method (Eq. 21). The relative contributions of the major uncertainty components to the total variance $u^{2}(Q)$ are given. Typically, for the new method the terms $u_{B, D}$ and $u_{c, e}$ are not presented since they are always negligible, except for the Doller case due to the integration method. Because it is always the predominating contribution in the ISO 748 method, the $u_{m}^{2} / u^{2}(Q)$ ratio is indicated, to be compared with the $\left[u_{m}^{2}(V, D)+u_{e d}^{2}(V)\right] / u^{2}(Q)$ ratio in the generalized method. Final uncertainties $U$ with a coverage factor $k=2$ (95\% confidence level) computed using both methods are also mentioned for comparison.

\begin{tabular}{c|c|c|c|c|c|c|c|c|c} 
name & $B / D / m$ & $\begin{array}{c}\text { max. } \\
\text { slope }\end{array}$ & $\alpha$ & $\begin{array}{c}\boldsymbol{U}(\boldsymbol{Q}) \\
(\text { new })\end{array}$ & $\begin{array}{c}u_{m}^{2}(V, D) \\
(\text { ratio) }\end{array}$ & $\begin{array}{c}u_{p}^{2} \\
(\text { ratio) }\end{array}$ & $\begin{array}{c}u_{\text {ed }}^{2} \\
\text { (ratio) }\end{array}$ & $\begin{array}{c}\boldsymbol{U}(\boldsymbol{Q}) \\
(\mathbf{I S O 7 4 8})\end{array}$ & $\begin{array}{c}u_{m}^{2} \\
\text { (ratio) }\end{array}$ \\
\hline Arc & 5.0 & $15^{\circ}$ & $15^{\circ}$ & $\mathbf{6 . 7 \%}$ & $95 \%$ & $5 \%$ & $0 \%$ & $\mathbf{5 . 2 \%}$ & $77 \%$ \\
Ardèche & 0.5 & $41^{\circ}$ & $40^{\circ}$ & $\mathbf{3 . 4 \%}$ & $81 \%$ & $19 \%$ & $0 \%$ & $\mathbf{5 . 1 \%}$ & $82 \%$ \\
Gignac & 0.2 & $0^{\circ}$ & $10^{\circ}$ & $\mathbf{2 . 7 \%}$ & $3 \%$ & $14 \%$ & $83 \%$ & $\mathbf{1 3 \%}$ & $98 \%$ \\
Laboratory & 0.6 & $3^{\circ *}$ & $5^{\circ}$ & $\mathbf{2 . 2 \%}$ & $3 \%$ & $64 \%$ & $33 \%$ & $\mathbf{3 . 5 \%}$ & $60 \%$ \\
Doller & 1.7 & $14^{\circ}$ & $15^{\circ}$ & $\mathbf{5 . 5 \%}$ & $62 \%$ & $4 \% * *$ & $2 \%$ & $\mathbf{9 . 8 \%}$ & $90 \%$
\end{tabular}

Table 2: Results of the uncertainty analysis of the stream discharge measurements test cases $\left(^{*}\right.$, the vertical wall between main channel and floodplain was ignored; ${ }^{* *}$ in this case, the contribution of $u_{c, e}^{2}$ is $32 \%$ ).

Salient results obtained for the five test cases using the generalized method and the ISO 748 method are summarized in Tab. 2. For each case, the bed variation angle, $\alpha$, was fixed at a realistic value, usually close to the maximum transverse slope seen in the bathymetry data of the discharge measurement verticals. The sensitivity of the computed uncertainty, $U(Q)$ (with coverage factor $k=2$ ), to the value of $\alpha$ is presented in Section 3.3 hereafter.

On average, the uncertainties $U(Q)$ computed with the proposed method are lower than the uncertainties $U(Q)$ computed with the ISO 748 method. The only exception is the Arc case, with a proposed estimate slightly higher than the ISO 748 estimate (6.7\% instead of 5.2\%). For 'standard' or 'almost standard' stream discharge measurements (Arc, Ardèche, Laboratory), uncertainty estimates appear to be consistent using one method or the other. For measurements with a reduced number of verticals (Gignac, Doller), the generalized method yields much lower uncertainty estimates than the ISO 748 method. In the case of the Gignac irrigation canal, an uncertainty level of $2.7 \%$ is more consistent than $13 \%$ with the expert knowledge from the hydrometry staff, and with verifications against concurrent discharge measurements (deviations were typically of the order of $3 \%$ ). 
Such differences in the computed $U(Q)$ stem from a greater variability in the contribution of the different error sources, when using the generalized method. The contributions of the major uncertainty components are investigated in the following sections.

\subsection{Uncertainty associated with the distribution of verticals}

As expected, when applying the ISO 748 method, the contribution of the $u_{m}$ term is high for every cases (see Tab. 2), even when the bottom geometry is constant (Gignac, 98\%) or when the number of verticals is extremely high (Laboratory, 60\%). As it takes into account not only the number of verticals but also their distribution and the expected maximum variation of the bed, the generalized method produces negligible contributions of the term $u_{m}(V, D)$ for these two cases. The uncertainty due to edge extrapolations, $u_{e d}$, only elicited in the generalized method, shows consistently negligible contributions to total variance for natural sections cases and high contributions for the canal cases (Laboratory, 33\%, Gignac, 83\%).

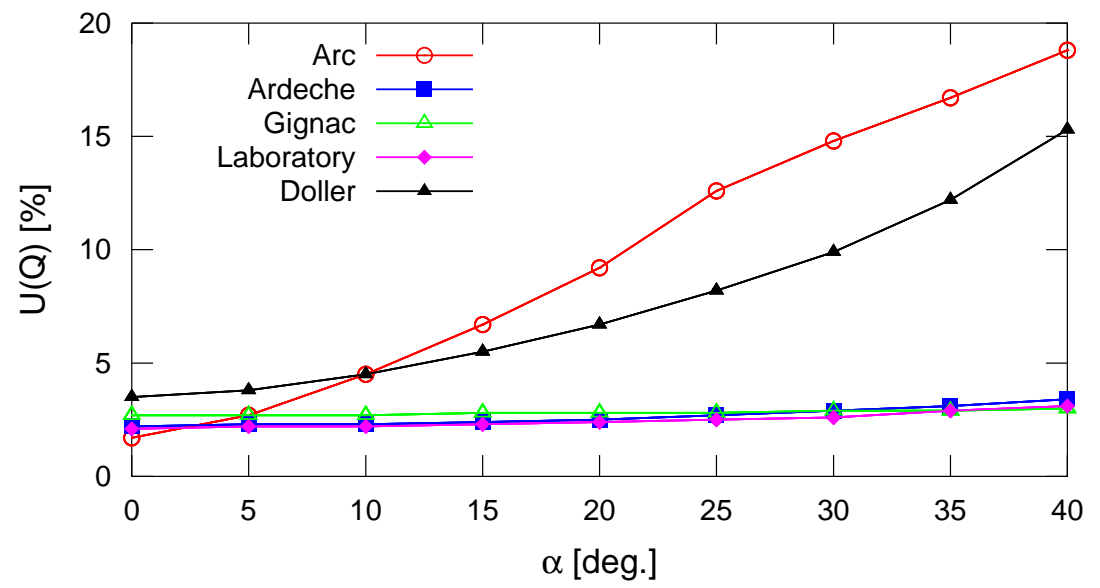

Figure 6: Influence of the bottom variation angle, $\alpha$, on the uncertainty $U(Q)(95 \%$ confidence level) computed following the generalized method, for all test cases.

The sensitivity of the uncertainty computed with the generalized method to the bottom variation angle, $\alpha$, was investigated using the five test cases (Fig. 6). Two contrasted behaviours can be observed. For cases with low subsection aspect ratios (Ardèche, Gignac, Laboratory, $B / D / m<1$ ), variations of $U(Q)$ with $\alpha$ are negligible. For cases with higher subsection aspect ratios (Doller: $B / D / m=1.7, \operatorname{Arc:~} B / D / m=5$ ), $U(Q)$ increases roughly linearly with $\alpha$, up to $15-20 \%$ for $\alpha=40^{\circ}$. Such a trend was expected based on the construction of the method for computing $u_{m}(D)$ and $u_{m}(V)$. It is logical that wide and shallow sections require more verticals than narrow and deep ones. With the $\alpha$ values fixed in accordance with the maximum slopes found in the measured bathymetry (see Tab. 2), the obtained values for $U(Q)$ appear to be realistic.

However, in case of flat sections with a limited number of verticals (i.e., high $B / D / m$ ratio), the assumption of a constant angle $\alpha$ may lead to overestimated values of $u_{m}(D)$ and $u_{m}(V)$. It should be kept in mind that this angle is primarily used to estimate the maximum error in subsection areas: in such flat cases, a realistic value for $\alpha$ should be quite lower than the local transverse slope of the bed. Other representation options could be tested such as an asymptotic increase of the bed line instead of an infinite slope with a fixed angle.

\subsection{Uncertainty associated with the vertical integration of velocity}

In most cases, the uncertainty components related to the measurement of velocity $\left(u_{s}, u_{c}, u_{e}\right)$ bring a negligible contribution compared to the uncertainty related to the vertical integration of velocity. Indeed, the contribution of $u_{c, e}^{2}$ is significant only for the Doller case (32\%), because the integration method was used.

The uncertainty component associated with the vertical integration of velocity, $u_{p}$, often brings a significant, though not dominant, part of the total uncertainty. It is particularly heavy in the Laboratory case, 
where the uncertainty could be decreased with a better sampling of velocity profiles, at least in the deeper main channel.

In order to assess the results of the proposed method for computing $u_{p}$ for the velocity distribution method, sensitivity tests were conducted using the Gignac dataset, which offers a large number (10) of velocity points located at normalized elevations above the bed. Tab. 3 presents the average values of $u_{p}$ over the six verticals, for different numbers of velocity points, using either reduced point methods or the velocity distribution method. Uncertainty values for reduced point methods are those provided by the ISO 748 [4] standard, extended with a power fit. The value indicated for 10 points $(0.5 \%)$ does not correspond to reduced point methods but is the value proposed by the ISO 748 standard for the velocity distribution method meeting all the requirements.

Computed $u_{p}$ for the velocity distribution method shows values that are consistent with the ISO 748 values, except when only 1 point is used: a dramatically high value (38\%, instead of $7.5 \%)$ is obtained because discharge extrapolation is then performed over the whole flow depth. Even if the value may seem exaggerated, it is not unlikely that using only one point for the velocity distribution method may lead to errors tremendously higher than using the robust 1-point reduced point method. According to the proposed computation method, the velocity distribution method applied to 2, 3, or 4 velocity points leads to standard uncertainties close to 5\% (68\% confidence level), higher than those related to the corresponding reduced point methods. For 5 or 6 points, uncertainty levels are similar. This is consistent with the expert knowledge of many hydrometry staffs. This is also because near-surface and near-bottom velocity measurements are used, reducing the contribution of top and bottom extrapolated discharges. At last, for the velocity distribution method applied to 10 points, the proposed method yields a slightly higher $u_{p}$ value than the ISO 748 default value. This value (1.2\%) remains realistic and negligible, if one recalls that the Gignac velocity measurements do not perfectly meet the ISO 748 requirements.

\begin{tabular}{c|c|c|c|c|c|c|c}
$p$ (number of points) & 1 & 2 & 3 & 4 & 5 & 6 & 10 \\
\hline$u_{p}$ (reduced point, ISO 748) & $7.5 \%$ & $3.5 \%$ & $3.0 \%$ & - & $2.5 \%$ & $2.0 \%$ & $0.5 \%^{*}$ \\
\hline$u_{p}$ (velocity distribution) & $38 \%$ & $4.8 \%$ & $4.6 \%$ & $4.6 \%$ & $2.4 \%$ & $2.3 \%$ & $1.2 \%$
\end{tabular}

Table 3: Uncertainty component $u_{p}$ due to the vertical integration of velocity, as computed applying the generalized method to the Gignac dataset. For a given number of velocity measurements, $p$, located at normalized elevations above the bed, both reduced point methods and velocity distribution method are considered (*value proposed in the ISO 748 standard for the velocity distribution method).

\section{Discussion}

\subsection{Instrumental and environmental errors}

The new generalized method confirms that integration errors in velocity-area discharge measurements are often, though not always, dominant on instrumental and environmental errors. In some cases however, one may wonder whether the latter error sources were not underestimated in the computation. When the computed combined uncertainty $U(Q)$ is very low (say, $<3 \%$ ), a better assessment of instrumental and environmental errors should certainly be necessary to obtain more realistic results. Typically, the very low uncertainty obtained for the Gignac and Laboratory cases $(U(Q) \approx 2 \%)$, or even for the Ardèche case $(U(Q) \approx 3 \%)$ call for a more comprehensive estimation of the instrumental uncertainty associated with the propellers used at these sites. Data from the current-meter calibration would help better quantify the corresponding terms $u_{s}$ and $u_{c}(V)$. In particular, the default value commonly used for $u_{s}(1 \%)$ may often be underestimated due to unproperly reported calibration data, calibration drift with time, or unappropriate instrument maintenance.

Though they are recognized to be of primary importance in streamflow measurements, environmental errors remain difficult to assess in an uncertainty analysis, because the mathematical model of their impacts is usually unknown or imperfectly known. Some environmental error sources are included in the computation and could be better parameterized thanks to additional studies. For instance, the velocity uncertainty $u_{e}(V)$ due to the limited sampling time of velocity fluctuations could be specifically quantified based on an evaluation of the turbulent time scales. However, many other environmental error sources are ignored, like 
the site-specific conditions which govern the velocity distribution, including obstacles, hydraulic works, wind, transient flow, etc. Also, the skill of the operators plays an important role: from current-meter intercomparison tests, Fulford et al. [8] found that a change in the operator introduced as much discharge uncertainty $(u \approx 2.5 \%$ ) as did a change in the current-meter. Deriving practical tools for quantifying the uncertainty related to such effects remains challenging. As a major environmental error source, simple considerations for assessing the uncertainty components due to variable flow are discussed in the following section.

\subsection{Additional errors due to variable discharge}

The discharge of a stream may significantly vary during the discharge measurement process, especially during floods or in case of infrastructure operations for instance. For the reasons stated in Section 1.3, the uncertainty due to the time-integration error of a varying discharge should be included in the uncertainty analysis of velocity-area discharge measurements. This time-integration error must be clearly distinguished from the hysteresis effect, which is not a discharge measurement error, but a deviation of the actual hydraulic conditions (discharge, water stage) from the usual stage-discharge relationship, due to transient flow effects in case of flood rise or fall. It is also useful to evaluate and correct the hysteresis effect when one wants to calibrate a steady-state stage-discharge relationship at a gauging station. Hereafter simple expressions for assessing both uncertainty components are proposed. Their validation as a practical tool would require further implementation tests.

Using a prior stage-discharge relationship $\bar{Q}(h)$ and the minimum and maximum water stages $\left(h_{\text {min }}\right.$, $h_{\text {max }}$ ) recorded during the discharge measurement, one can quantify the maximum discharge error due to varying discharge, hence the standard uncertainty assuming a rectangular distribution [1]:

$$
u_{v a r}=\frac{\left(\bar{Q}\left(h_{\max }\right)-\bar{Q}\left(h_{\min }\right)\right)}{2 \sqrt{3} Q_{m}}
$$

with $Q_{m}$ the time-averaged measured discharge.

To approximate the hysteresis effect, the classical Jones [11] formula usually yields acceptable results:

$$
Q_{r}=Q_{m} \sqrt{1+\frac{1}{S_{r} C_{w}} \frac{d h}{d t}}
$$

with $Q_{m}$ measured discharge, $Q_{r}$ discharge corrected for unsteady effect, $S_{r}$ energy slope in the reference conditions, $C_{w}$ celerity of the flood wave, $d h / d t$ time evolution of the water stage. $C_{w}$ may be approximated by:

$$
C_{w}=\frac{1}{B} \frac{d \bar{Q}}{d h}
$$

with $B$ the bankfull width and $d \bar{Q} / d h$ the local slope of the rating curve (stage-discharge relationship).

Assymetric uncertainty would be the most accurate quantification of the hysteresis error. In a simpler manner, the standard uncertainty may be quantified from the Jones correction taken as the maximum discharge error, and assuming a rectangular distribution [1]:

$$
u_{h y s t}=\frac{\left|Q_{m}-Q_{r}\right|}{2 \sqrt{3} Q_{m}}
$$

Since these two error sources are independent of the previously identified error sources, the resulting variances $u_{v a r}^{2}$ and $u_{\text {hyst }}^{2}$ may be simply added to the variance sum in Eq. 11.

\subsection{Strategy for reducing integration errors}

Uncertainty analysis is useful to help practitioners define the best strategy for reducing integration errors that affect their velocity-area discharge measurements. The best spatial integration strategy consists of minimizing the number $m$ of verticals and the number $p$ of point velocity measurements while keeping 
the uncertainty $U(Q)$ at a satisfactory level. The new tool can be used to perform sensitivity analysis in order to define this best strategy at a given site under given flow conditions and technical constraints.

An interesting innovative strategy consists of adding some verticals where only flow depth is measured and where depth-averaged velocity is interpolated. The advantage arises from the following ideas: the depth-averaged velocity cross-profile is usually smoother and less variable than the bed geometry crossprofile; at a vertical, the time needed to measure flow depth is negligible compared to the time needed to measure velocity, due to the number of points and the time of exposure. As already introduced in Section 2.3, several authors $[7,3,5,13]$ reported the successful interpolation of depth-averaged velocities based on assumed linear variation of the Froude number, or equivalently the Chézy coefficient, throughout the cross-section. Following this assumption, at a vertical where only $d_{j}$ was measured, the ratio $\overline{v_{j}} / \sqrt{d_{j}}$ can be linearly interpolated from the closest verticals where both depth and mean velocity were measured.

The uncertainty in the interpolated depth-averaged velocity, $u_{p}\left(\overline{v_{j}}\right)$, stems from the interpolation itself and from the uncertainty in the measured velocities used in the interpolation. Considering that these error sources are independent, the corresponding variances can be added. Since the velocity cross-profile is likely convex, the maximum interpolation error may be estimated by $\left(\overline{v_{j+1}}-\overline{v_{j-1}}\right) / 2$. Therefore, assuming a rectangular probability density function for the interpolation error [1], the following estimation of $u_{p}\left(\overline{v_{j}}\right)$ can be suggested:

$$
u_{p}^{2}\left(\overline{v_{j}}\right)=\left(\frac{\overline{v_{j+1}}-\overline{v_{j-1}}}{2 \sqrt{3}}\right)^{2}+u_{p}^{2}\left(\overline{v_{j-1}}\right)+u_{p}^{2}\left(\overline{v_{j+1}}\right)
$$

As an example, such a strategy was tested on the Arc case using the generalized uncertainty computation method by varying the number $m_{1}$ of verticals with depth and velocity measurements (velocity verticals) and the number $m_{2}$ of verticals with depth measurements only (bathymetry verticals). In addition to the original dataset with 20 conventional verticals (Fig. 7a), modified datasets were also processed adding one bathymetry vertical between each pair of velocity verticals (Fig. 7b), removing one velocity vertical out of two (Fig. 7c), turning one velocity vertical out of two into a bathymetry vertical (Fig. 7d).

Tab. 4 shows the final uncertainty, $U(Q)$, along with the variance contributions of the transversal integration uncertainty, $u_{m}(V, D)$, and of the vertical integration uncertainty, $u_{p}$. In the Arc case, whatever the tested strategy, other uncertainty components are negligible compared to integration uncertainty components which bring roughly $100 \%$ of the total variance. The computed discharge $Q$ is roughly invariable (within $0.5 \%$ except for 10 verticals only, $-1.5 \%$ ). It is interesting to see that turning half of the verticals into bathymetry verticals with velocity interpolation yields very similar discharge and uncertainty $(U(Q) \approx 7 \%)$ as the reference case. This would be a good strategy since the measuring time would be approximately $30 \mathrm{~min}$ instead of 1 hour, typically. When velocity interpolation is not performed, uncertainty is much higher: $U(Q) \approx 20 \%$. When velocity verticals are doubled with bathymetry verticals, the uncertainty is estimated as low as $\sim 3 \%$, for an equivalent field work time as initially.

\begin{tabular}{c|c|c|c|c|c|c} 
name & $m_{1}$ & $m_{2}$ & $\begin{array}{c}Q \\
\mathrm{~m}^{3} / \mathrm{s}\end{array}$ & $\begin{array}{c}U(Q) \\
(\text { new })\end{array}$ & $\begin{array}{c}u_{m}^{2}(V, D) \\
\text { (ratio) }\end{array}$ & $\begin{array}{c}u_{p}^{2} \\
(\text { ratio })\end{array}$ \\
\hline Arc & 20 & 0 & 15.54 & $6.7 \%$ & $95 \%$ & $5 \%$ \\
Arc2 & 20 & 19 & 15.49 & $2.9 \%$ & $70 \%$ & $30 \%$ \\
Arc3 & 10 & 0 & 15.29 & $20 \%$ & $89 \%$ & $11 \%$ \\
Arc4 & 11 & 9 & 15.47 & $7.4 \%$ & $82 \%$ & $18 \%$
\end{tabular}

Table 4: Results of the uncertainty analysis conducted on the Arc test case for different spatial sampling strategies. 
(a) Arc
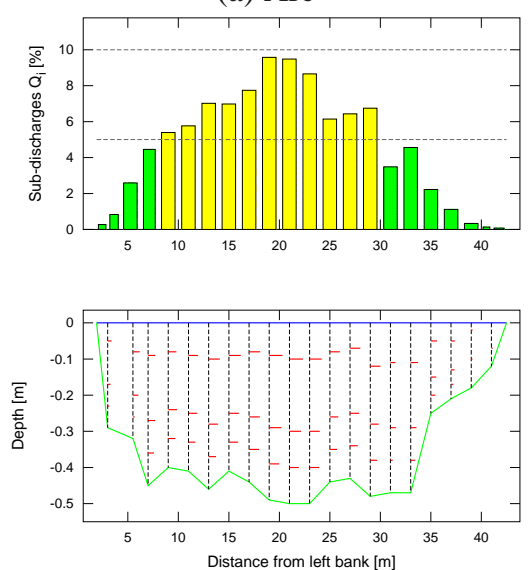

(c) $\operatorname{Arc3}$
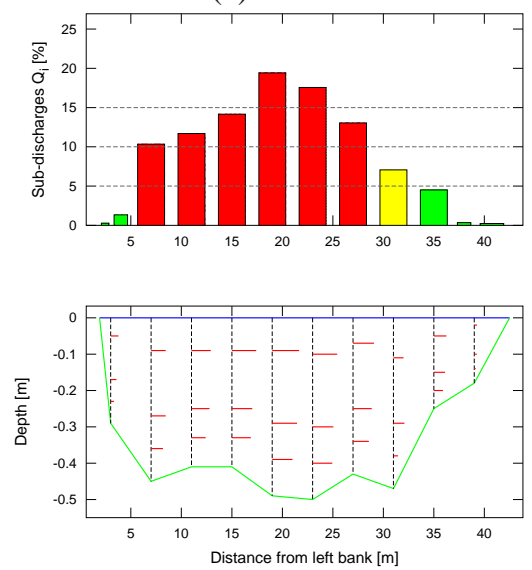

(b) Arc2
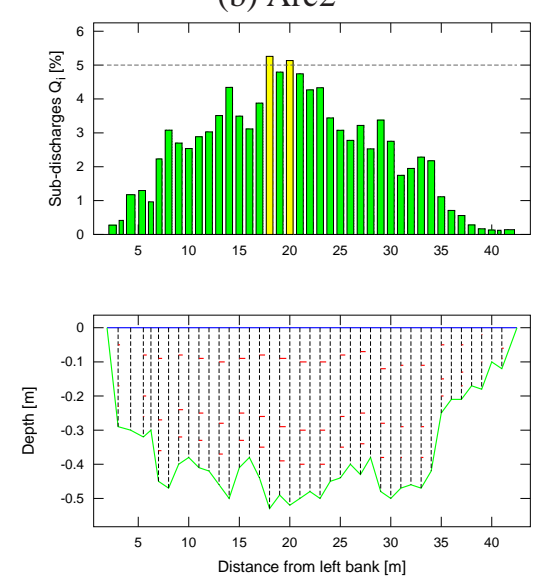

(d) Arc4
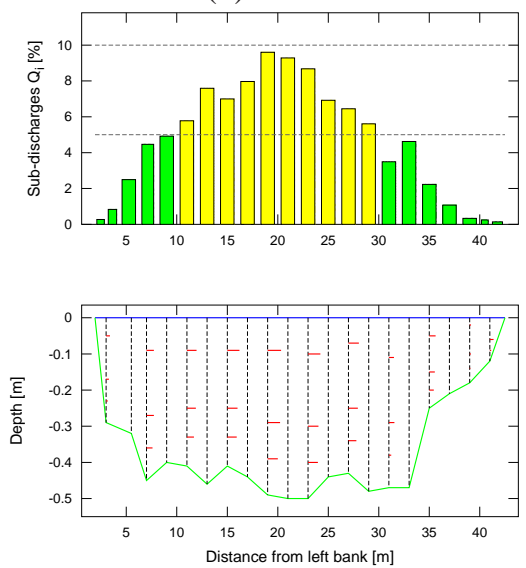

Figure 7: Test case Arc-en-Maurienne at Saint-Avre: original measurements (Arc, a); modified with one additional bathymetry vertical between each velocity vertical pair (Arc2, b); modified with one velocity vertical out of two removed (Arc3, c); modified with one velocity vertical out of two turned into a bathymetry vertical $(\operatorname{Arc} 4, d)$. 


\section{Conclusions}

A new method for computing uncertainty in velocity-area discharge measurements was developed and tested successfully on a range of test cases. This method was built as a generalization of the conventional method of the ISO 748 [4] standard to cope with identified drawbacks of the latter method. In particular, direct computation methods for spatial integration uncertainty components $\left(u_{p}\left(V_{i}\right), u_{m}\left(D_{i}\right), u_{m}\left(V_{i}\right)\right)$ were proposed instead of the informative values tabulated in the ISO748 standard. Discharge extrapolations to the edges and in the top/bottom layers are explicitly taken into account, as well as the distribution of the verticals throughout the cross-section. Another advantage is that uncertainty due to spatial sampling of depth and of velocity are separated. Only one additional parameter is introduced: the angle $\alpha$ accounting for the maximum likely area error between two verticals. Guidelines for choosing the value of $\alpha$ were provided, as well as a sensitivity analysis.

The new method appears to be more versatile though as simple and robust as the ISO 748 method. It can be easily implemented in usual discharge computation software. Using the proposed method, similar results were obtained for standard measurements conducted in natural sections, while more variable and more relevant uncertainty levels were computed for less standard cases, especially in man-made canals with simple shape and low width-to-depth ratio $(B / D<10)$. Despite further validation tests still need to be conducted, the method already provided interesting results, especially in terms of the contribution of the different error sources. Most often, integration errors are dominant on instrumental and environmental errors. Without increasing the field work time significantly, integration errors can be reduced using additional verticals where depth is measured and velocity is interpolated. When the total uncertainty is computed to be very low $(U(Q)<3 \%)$, instrumental and environmental errors which may have been underestimated or ignored should be kept in mind. Especially, additional errors due to variable discharge should be evaluated. Simple equations to compute both time-integration error and hysteresis effect due to transient flow were proposed to complete the uncertainty analysis.

As a perspective, the generalized uncertainty method could be extended to other discharge measurement techniques derived from the velocity-area method, namely surface velocity measurements and acoustic Doppler current profilers (ADCP).

Surface velocity measurements appear to be particularly useful in tough flood conditions when intrusion of instruments within the flow may be dangerous or impossible. They can be conducted with a variety of techniques ranging from current-meter mounted on a torpedo, natural or artificial floats, image sequence analysis, to radar Doppler velocimetry. The assessment of the uncertainty in point surface velocity measurement should be adapted to the specific instrumentation used. Additional uncertainty arises due to the necessary conversion of surface velocity to depth-averaged velocity and due to assumption on the bathymetry when it cannot be measured simultaneously with surface velocity. The surface velocity conversion is usually done using a constant coefficient. Based on theoretical and empirical studies of the variability of that velocity coefficient (e.g., 14), the corresponding standard uncertainty can be estimated to range between $5 \%$ and $10 \%$, which is consistent with the value of $u_{p}(7.5 \%)$ for the 1-point method according to the ISO 748 standard.

The proposed method can also be extended almost directly to ADCP measurements when they are conducted in a stationary way (vertical by vertical). However, ADCP are usually deployed following the mobile boat technique which relies on a different mathematical model than the velocity-area method. The development of a dedicated methodology for computing the uncertainty in mobile ADCP discharge measurements is still an open scientific issue (e.g., 15).

\section{Acknowledgements}

This research task was supported by SCHAPI (French Environment Ministry) and Irstea. The operators who produced all the data and information used in this study are gratefully acknowledged, especially Thierry Pantel (CNR), José Ribot-Bruno (Irstea Montpellier), Fabien Thollet and Yann Peltier (Irstea Lyon), and Guillaume Philips and Daniel Moritz (DREAL Alsace). 


\section{References}

[1] GUM (2008) Evaluation of measurement data - Guide to the expression of uncertainty in measurement, JCGM member organizations (BIPM, IEC, IFCC, ILAC, ISO, IUPAC, IUPAP and OIML), $120 \mathrm{p}$.

[2] ISO/TS 25377 (2007). Hydrometric Uncertainty Guidance (HUG), International Organization for Standardization, Geneva, Switzerland, $51 \mathrm{p}$.

[3] ISO/TR 9823 (1990). Liquid flow measurement in open channels. Velocity-area method using a restricted number of verticals, International Organization for Standardization, Geneva, Switzerland, 16 p.

[4] ISO 748 (2007). Hydrometry - Measurement of liquid flow in open channels using current-meters or floats, International Organization for Standardization, Geneva, Switzerland, $46 \mathrm{p}$.

[5] Boiten W. (2000). Hydrometry, Francis and Taylor publishers, 242 p.

[6] Carter, R.W., and Anderson, I.E. (1963). Accuracy of current meter measurements. Journal of the Hydraulics Division. Proc. ASCE, HY4, 105-115.

[7] Fulford, J., Sauer, V. (1986). Comparison of velocity interpolation methods for computing open-channel discharge. U.S. Geological Survey Water-supply Paper 2290, 139-144.

[8] Fulford, J.M., Thibodeaux, K.G., and Kaehrle, W.R. (1994). Comparison of current meters used for stream gaging. In: Fundamentals and Advancements in Hydraulic Measurements and Experimentation, August 1-5, 1994, American Society of Civil Engineers, New York, NY, pp. 376-385.

[9] Herschy, R.W. (1999). Hydrometry, Principles and Practices, Second edition, Wiley, 376 p.

[10] Herschy, R.W. (2002). The uncertainty in a current meter measurement. Flow Measurement and Instrumentation, 13, $281-284$.

[11] Jones, B.E. (1916). A method of correcting river discharge for a changing stage. Water Supply Paper 375, U.S. Geological Survey, 117-130

[12] Kiang, J.E., Cohn, T.A., Mason, R.R. (2009). Quantifying uncertainty in discharge measurements: A new approach. World Environmental and Water Resources Congress 2009: Great Rivers, 342, 5924-5931

[13] Le Coz, J., Pierrefeu, G., Paquier A. (2008). Evaluation of river discharges monitored by a fixed side-looking Doppler profiler, Water Resources Research, 44, W00D09, doi:10.1029/2008WR006967.

[14] Le Coz, J., Hauet, A., Dramais, G., Pierrefeu, G. (2010). Performance of image-based velocimetry (LSPIV) applied to flashflood discharge measurements in Mediterranean rivers, Journal of Hydrology, 394, 42-52, doi:10.1016/j.jhydrol.2010.05.049.

[15] Muste, M., Yu, K., Gonzalez-Castro, J., Starzmann E. (2004). Methodology for Estimating ADCP Measurement Uncertainty in Open-Channel Flows, Proceedings World Water \& Environmental Resources Congress 2004 (EWRI), Salt Lake City, USA

[16] Olivier, A., Pierrefeu, G., Scotti, M., Blanquart, B. (2009). Incertitude des mesures de débit réalisées à l'ADCP (Uncertainty in discharge measurements conducted with an ADCP, in French). La Houille Blanche, 3, 132-137, doi:10.1051/lhb/2009037.

[17] Pelletier, P.M. (1988). Uncertainties in the single determination of river discharge: a literature review. Canadian Journal of Civil Engineering, 15, 834-850.

[18] Rantz, S. E. (1982). Measurement and computation of streamflow. Vol. 1, Measurement of stage and discharge, Water-Supply Paper 2175. U. S. Geological Survey, Washington.

[19] Sauer, V.B. (1992). Determination of error in individual discharge measurements. USGS Open-File Report 92-144, 21 p.

\section{List of symbols}

$\begin{array}{ll}\Delta X & {[X \text { unit] }} \\ \alpha & {[\mathrm{deg} .]} \\ & \\ B & {[\mathrm{~m}]} \\ B_{i} & {[\mathrm{~m}]} \\ C_{w} & {[\mathrm{~m} / \mathrm{s}]} \\ D & {[\mathrm{~m}]} \\ D_{i} & {[\mathrm{~m}]} \\ N & {[-]} \\ Q & {\left[\mathrm{~m}^{3} / \mathrm{s}\right]} \\ \bar{Q}(h) & {\left[\mathrm{m}^{3} / \mathrm{s}\right]} \\ Q_{i} & {\left[\mathrm{~m}^{3} / \mathrm{s}\right]} \\ Q_{m} & {\left[\mathrm{~m}^{3} / \mathrm{s}\right]} \\ Q_{r} & {\left[\mathrm{~m}^{3} / \mathrm{s}\right]} \\ R_{h} & {\left[\mathrm{~m}^{3} / \mathrm{s}\right]} \\ S_{i} & {\left[\mathrm{~m}^{2}\right]} \\ S_{r} & {[-]} \\ U & {[\%]} \\ V_{1 / N} & {[\mathrm{~m} / \mathrm{s}]} \\ V_{i} & {[\mathrm{~m} / \mathrm{s}]} \\ X & {[X \text { unit }]}\end{array}$

maximum error in measurand $X$

angle accounting for the maximum bottom transverse slope

bankfull section width

width of subsection $i$

celerity of the flood wave

average section depth

mean depth of subsection $i$

number of discharge subsections

total discharge across the section

stage-discharge relationship

sub-discharge or discharge of subsection $i$

time-averaged measured discharge

discharge corrected for unsteady effect

hydraulic radius

subsection area $S_{i}=B_{i} D_{i}$

energy slope in the reference conditions

final uncertainty expressed using a coverage factor $k=2$ (95\% level of confidence)

edge subsection velocity $(i=1$ or $i=N)$

mean velocity of subsection $i$

measurand 


\begin{tabular}{|c|c|}
\hline$d$ & {$[\mathrm{~m}]$} \\
\hline$d_{j, k}$ & {$[\mathrm{~m}]$} \\
\hline$h$ & {$[\mathrm{~m}]$} \\
\hline$i$ & {$[-]$} \\
\hline$j$ & {$[-]$} \\
\hline$k$ & {$[-]$} \\
\hline$m$ & {$[-]$} \\
\hline$m_{1}$ & {$[-]$} \\
\hline$m_{2}$ & {$[-]$} \\
\hline$m_{b}$ & {$[-]$} \\
\hline$m_{1 / N}$ & {$[-]$} \\
\hline$n$ & {$[-]$} \\
\hline$q$ & {$\left[\mathrm{~m}^{2} / \mathrm{s}\right]$} \\
\hline$q_{b o t}$ & {$\left[\mathrm{~m}^{2} / \mathrm{s}\right]$} \\
\hline$q_{\text {meas }}$ & {$\left[\mathrm{m}^{2} / \mathrm{s}\right]$} \\
\hline$q_{\text {top }}$ & {$\left[\mathrm{m}^{2} / \mathrm{s}\right.$} \\
\hline$u(X)$ & {$[\%]$} \\
\hline$u(B, D)$ & {$[\%]$} \\
\hline$u_{c}$ & {$[\%]$} \\
\hline$u_{c, e}$ & [\%] \\
\hline$u_{e}$ & {$[\%]$} \\
\hline$u_{e d}$ & {$[\%]$} \\
\hline$u_{\text {hyst }}$ & [\%] \\
\hline$u_{m}$ & {$[\%]$} \\
\hline$u_{p}$ & [\%] \\
\hline$u_{s}$ & {$[\%]$} \\
\hline$u_{v a r}$ & {$[\%]$} \\
\hline $\bar{v}$ & {$[\mathrm{~m} / \mathrm{s}]$} \\
\hline$v_{j, k}$ & {$[\mathrm{~m} / \mathrm{s}]$} \\
\hline$y$ & {$[\mathrm{~m}]$} \\
\hline
\end{tabular}

local water depth

velocity measurement depth

water stage

subsection index $(1 \leq i \leq N)$

vertical index $(1 \leq j \leq m)$

velocity point index

number of measurement verticals

number of verticals with depth and velocity measurements (velocity verticals)

number of verticals with depth measurements only (bathymetry verticals)

bed roughness parameter (inverse of the power function exponent)

edge roughness parameter (inverse of the power function exponent)

number of independent velocity measurements per vertical

$\left(\mathrm{m}^{2} / \mathrm{s}\right)$ discharge per unit width

discharge per unit width in the extrapolated top layer of the vertical velocity profile

discharge per unit width in the measured middle layer of the vertical velocity profile

discharge per unit width in the measured bottom layer of the vertical velocity profile relative standard uncertainty (in $\%$ of measurand $X$ )

relative standard uncertainty accounting for random errors in width and depth measurements

relative standard uncertainty accounting for random errors in point velocity measurements due to the limited current-meter accuracy

relative standard uncertainty accounting for random errors in point velocity measurements due to the limited current-meter accuracy and the limited time of exposure

relative standard uncertainty accounting for random errors in point velocity measurements due to time-averaging of turbulent fluctuations over the time of exposure

relative standard uncertainty related to the velocity extrapolated in the edge subsection relative standard uncertainty accounting for errors due to hysteresis effects

relative standard uncertainty accounting for errors due the limited number $m$ of verticals relative standard uncertainty accounting for errors due to the limited number $n$ of point velocity measurements over the vertical

relative standard uncertainty accounting for systematic errors

relative standard uncertainty accounting for errors due to variable discharge

depth-averaged velocity

point velocity perpendicular to the cross-section measured at depth $d_{j, k}$ at vertical $j$

position from the start edge 